\title{
A Risk-averse Analysis of Overseas Acquisition
}

\author{
Huan Zhu ${ }^{1, a}$, Liankai Liao ${ }^{1, b}$ \\ ${ }^{1}$ School of Management, Wuhan University of Technology, Wuhan, P. R. China \\ atianyinanbei@163.com, ${ }^{b}$ liaoliankai@163.com
}

Keywords: CNOOC, Nexen, Overseas Mergers and Acquisitions.

Abstract: As we all know, the deal that CNOOC successful merged with Nexen in 2013 was the biggest in China. Combined with the reality, this paper briefly reviews the process and reveals the key problems in this merger ${ }^{[1]}$. Then some relevant recommendations are provided in the cultural, technical, financial and political aspects.

\section{Introduction}

With the trend of economic globalization, the number of cases about overseas mergers and acquisitions are increasing. The international economic environment is so fickle and complicated that lots of firms can not complete the plan of acquisitions. Absolutely, the challenges of investing overseas can not be underestimated. The paper is expected to offer some consideration to some enterprises about risk aversion in overseas acquisitions.

\section{Research status}

The current situation of overseas research. The waves of M\&A have been formed for five times in all in the west until now. For the first one, it took place with the horizontal M\&A tide between small companies form 1880 to 1918. It can draw our attention to the fact that there were more than seventy major enterprises recombined from about one hundred and fifty small firms. Secondly, in the next eleven years, transforming from one to the other one, the main part of M\&A was vertical combinations. And then, the scale was expanded into Europe and North America due to the significant economic benefits. The dramatic increase in the deals of conglomerate M\&A was remarkable. Following that, the way of M\&A became diversified between 1980-1990. Lastly, multinational M\&A arrived in quick succession.

Domestic research status. The development of M\&A in China have experienced the following stages. On the early stage side, reconstructions always occurred within the same industry on a small scale. After property rights have been transferred throughout the country, the capital market of our country was in the phase of normalization. And so many listed firms promoted the optimal allocation by share purchase on the rapid development stage. Form then on, the market entered a upgrading period.

\section{Review the process of Nexen-CNOOC Merger}

On July 23, 2012, CNOOC announced that CNOOC Canada Holding Ltd., a wholly-owned subsidiary of CNOOC in Canada, had come to an agreement with Nexen about the transaction. According to the agreement, CNOOC Canada Holding Ltd., the buyer, should purchase all the preferred stocks, common stocks and stock options of Nexen. It would cost $\$ 151$ billion, not counting the debt which the buyer should replace Nexen to pay back the debt about $\$ 43$ billion $^{[2]}$. 


\section{Venture analysis}

Culture diversity. Accounting to transnational mergers and acquisitions, every enterprise is in the face of a severe threat of improper cross-cultural management. So without wisdom, CNOOC would have been more possible to fear poor performance as a result of inappropriate management. Overall, this chapter will show a detailed explanation of culture and system diversities.

Firstly, culture differences would contribute to the mental conflict. Working for new employer, the degree of loyalty and identity can be lowered. And even CNOOC employees would not work hard as before ${ }^{[3]}$. That can be a tricky problem for team building. The difference in social system and ideology increases the difficulty of enterprise 's multicultural management.

Secondly, the cultural conflicts of these two types appear as a series of conflicts in system. Such as a salary system, a holiday system, a work system and so on, CNOOC staffs have be accustomed to it. If those were changed, they would be disgusted with new systems ${ }^{[4]}$. Take salary for example, basic month salary in Canada must be higher than in China. How to deal with the problem of the pay discrepancies can be the key to workers.

Financing risk. Large state-controlled enterprises always choose to keep the stability of stock construction comparatively, including $\mathrm{CNOOC}^{[5]}$. As a result of it, CNOOC seldom issued additional stocks to make fund-raising. Equity financing aside, debt financing can bring some hidden troubles. CNOOC should get a plan for all debt repayment of Nexen regardless of short- or long- term debt. To complete the deal, its debt increased nearly sixty-five percent. Reputational risk can come along with the capital and interest. On the other hand, so much debt will increase the risk of operation in the corporation.

Political struggle. Seeing the deal as a political act, the opposition in Canada against the plan that CNOOC, a state owned corporation (SOC for short) in China, bought out Nexen to steal technical information. Certainly, political risk is inevitable.

Other risk factors. All other risk factors in this article derives from integration after M\&A, such as human resource integration risks, technology integration risks and so on ${ }^{[5]}$. Lacking of advanced international talents, the company tends to be uncompetitive because of decision-making errors. Expanding into new areas, CNOOC possessed the characteristic of poor techniques. And these problems should not be neglected.

\section{Relative suggestions}

The financing way's diversification. Combined with the effect of the financial leverage, CNOOC made use of the mix of debt financing and internal financing ${ }^{[6]}$. Obviously, using their own funds about $\$ 9$ billion can reduce the cost of capital and avoid seeing their stakes diluted.

Table 1. Relevant indexes of short-term liquidity

\begin{tabular}{|c|c|c|c|c|}
\hline $\begin{array}{c}\text { Index } \\
\text { Year }\end{array}$ & 2009 & 2010 & 2011 & 2012 \\
\hline current ratio & 1.96 & 1.76 & 1.88 & 2.07 \\
\hline quick ratio & 1.8 & 1.85 & 2.2 & 2.01 \\
\hline asset-liability ratio & $63 \%$ & $59 \%$ & $54 \%$ & $55 \%$ \\
\hline
\end{tabular}

And the rest about $\$ 6$ billion was afforded by the bank, which is viewed as the rapid financing facility. Referring to the table 1 above, which is figured out from the financial statements in the past years, we can know that current ratio of CNOOC was about 2.07 in 2012, with year-on-year growth of $10 \%$. And quick ratio was far more than 1 , which is normal for other firms. These can tell us that the ability of immediate debt paying is powerful. In conclusion, only 
by detailed self analysis of ability to pay and the cash flow status can firms make favorable financing strategies.

Resolve political contradiction. There are lessons emerged from these events, which should be learned. One is election, CNOOC chooses the corporation in Canada, which have good diplomatic relations with our country ${ }^{[7]}$. And then, taking the interests of Canada into consideration, SOCs can make it more likely to come to terms. As we all know, all employees in Nexen had been retained. Lastly, firms can explain the act as business dealings by virtue of foreign subsidiary to avoid politic risk.

The realization of synergies. Synergistic effect is not only a main motivation of M\&A, but also the key to a successful M\&A. The effective integration reflects synergistic effect. In the first place, a new value system should be set up to reduce the cultural differences ${ }^{[3]}$. And then, the relative important thing is technological learning ${ }^{[8]}$.To realize advantageous complementarities and promote common development, CNOOC had sent some delegates to develop and absorb new technologies. Thirdly, another requirement for the deal is to develop professional talents. Undoubtedly, resources of Nexen can be taken full of, efficient reconstruction leads to enterprise value maximization $^{[9,10]}$.

\section{Summary}

Enterprises in China and western will have access to overseas resources through M\&A. They can not maximize enterprises benefits, but only on the condition of avoiding hidden risks. SO Nexen-CNOOC Merger has a vital significance for other firms.

\section{Acknowledgement}

The acknowledgments are given to the school of Management, Wuhan University of Technology. Special thanks are given to my supervisor Mr. Liao for elaborate guide in entire work.

\section{References}

[1] Walker R. Cnooc's Triple happiness[J]. Financeasia, 2013.

[2] Woodworth C. Chinese Oil Giant Pays Big For Canadian Producer Nexen[J]. Energy Daily, 2012.

[3] Yang F. Cultural conflict and integration in overseas mergers and acquisitions[C]//Business Management and Electronic Information (BMEI), 2011 International Conference on. IEEE, 2011:96-98.

[4] Cheng D J. A Review and Trend of Cultural Risk Research on Overseas M\&A for Chinese Enterprises[J]. Journal of Guangxi University of Finance \& Economics, 2014.

[5] Boothe P. STATE-OWNED ENTERPRISES AND FOREIGN INVESTMENT IN CANADA[J]. Ivey Business Journal, 2013.

[6] Hale G. CNOOC-Nexen, State-Controlled Enterprises and Canadian Foreign Investment Policies: Adapting to Divergent Modernization[J]. Canadian Journal of Political Science, 2014, 47(2):349-373.

[7] Erica S. Downs. Who’s Afraid of China’s Oil Companies?[J]. Brookings Institution Press, 2010.

[8] Sun W B. On risk prevention of the mergers and acquisitions about China's enterprises[J]. Technological Development of Enterprise, 2009. 
[9] Roy J A M. An Event Study Analysis of the Nexen-CNOOC Takeover: Implications for the Canadian Market[J]. 2013.

[10] Analyst N M M B C. Nexen-CNOOC Merger can Benefit Canada: Analyst[J]. Fox Business. 